\title{
EDUARD HANSLICK'S FORMALISM AND HIS MOST INFLUENTIAL CONTEMPORARY CRITICS
}

\begin{abstract}
The paper deals with the formalistic view on music presented in Eduard Hanslick's treatise On the Musically Beautiful, which is taken to be the founding work of the aesthtetics of music. In the paper I propose an interpretation of Hanslick's treatise which differs on many points from the interpretations displayed in the works of several most influential contemporary aestheticians of music. My main thesis is that Hanslick's treatise is misunderstood and incorrectly presented by these authors. I try to demonstrate this thesis by referring to Hanslick's original formulations in the German edition and by showing that my interpretation renders Hanslick's view far more coherent and his arguments successful in showing his main conclusions. Accepting this alternative interpretation should have further implications on many contemporary theories in the aesthetics of music that reckon on the failure of Hanslick's arguments as presented by usual interpretations.
\end{abstract}

Key words: $\quad$ aesthetics of music, Eduard Hanslick, formalism

\section{Introduction}

Eduard Hanslick is considered the founding father of the aesthetics of music. His treatise On the Musically Beautiful ${ }^{1}$ has had such a great impact on the understanding of music, that today, almost all of the authors who write about music from a philosophical perspective, especially about music's relation to emotions, first state their attitude toward Hanslick's view, and only then present and defend their own view. In contemporary literature on music, a distinction is made between the so-called Hanslickians and Hanslick's critics, although all of them mostly reject all of his arguments. In this paper, I shall not deal with contemporary authors' attempts to establish their own theories. Rather, I will focus on their interpretations of the treatise On the Musically Beautiful, since, in my opinion, that is where a more fundamental, and also more interesting point can be found. Namely, I will argue that Hanslick's treatise (or „little book”

1 I will comparatively follow Geoffrey Payzant's translation: Eduard Hanslick, On the Musically Beautiful, trans. Geoffrey Payzant, Indianapolis, 1986. (in further text -OMB), for it is this translation that contemporary authors refer to, and Ivan Foht's translation: Eduard Hanslik, $O$ muzički lijepom, pr. Ivan Foht, BIGZ, 1977. (in further text - OML), because it is more faithful to the original than Payzant's, which partly engages in interpreting the text. In addition, I will provide parts of the original text when mentioning contentious or key terms: Eduard Hanslick, Vom Musikalisch-Schönen, 13.-15. Auflage, Leipzig, 1922. (in further text - VMS). 
as it is called by some of these authors) is superficially read by these authors, and mostly misunderstood. This fact should reflect considerations that follow from the mentioned misunderstanding. In this paper, I shall offer a more precise reconstruction of Hanslick's argumentation. After that, I shall present interpretations of Hanslick's view by several most influential contemporary authors, followed by a demonstration that there is a discrepancy between these interpretations and the text of the treatise. The aim of the paper is to prove a possibility of a different interpretation of Hanslick's treatise, which I consider not only to correspond to the text of the treatise better, but also to present it as more coherent than other interpretations do.

Firstly, I will try to explain the so-called negative thesis, which is what Hanslick is most occupied with in his treatise. Explicitly, Hanslick only writes that his negative thesis "first and foremost opposes the widespread view that music is supposed to 'represent (darstellen) feelings.', "2 In elaboration and demonstration of this thesis, Hanslick will examine other relations of music and feeling, relations that will be more interesting to the contemporary aestheticians of music. Contemporary authors do not follow Hanslick's line of argumentation, but rather directly go in for the assertions and conclusions that they are interested in. However, I will here hang on to Hanslick's course of exposure, since I believe his work to be far more coherent than it seems at first, and also that neglecting the relations between certain arguments easily leads to misunderstanding of Hanslick's assertions and intentions.

While the explicit statement of the negative thesis does not say much, broadly, the thesis includes critique and rejection of then widespread apprehension of music, which Hanslick ironically names "the emotional aesthetics." It is a view, which, according to Hanslick, attributes a double role to emotions in the art of music: firstly, that the arousal of emotions is what defines music and the purpose of music (Zweck und Bestimmung); secondly, that emotions are the content of music, "that which musical art represents in its works." ${ }^{3}$ Hanslick rejects both of these roles, and his arguments against them constitute the negative part of the treatise. In the next section, I will discuss what exactly Hanslick means by these two roles and how he dismisses them. First, I shall consider how the definition and purpose of music should be understood.

\section{The first role: (aroused) as the defining purpose of music}

Considering this role, music is understood from a functionalist point of view: fulfilling a certain unartistic function or purpose (such as the arousal of emotions) is the specificity of music - it is what music does and what determines it as music. At the same time, fulfilling of this purpose is what music is supposed

2 See OMB, p. xxii, OML, p 36-7. I will accept represent the correct translation of the term darstellen. Hanslick explicates this term as following: to represent is to produce a clear and distinct content, to «put» (or present) it «before» our very eyes (»daher stellen«) - see OMB, p. 14, OML, p. 66. Contrary to Payzant's translation of this term as represent, contemporary authors mostly speak of expression or expressiveness, which Hanslick names as ausdrücken throughout the whole treatise.

3 See OMB, p. 3, OML, p. 41-2. 
to do, a task it has to accomplish. This, as it turns out, descriptive-normative definition (since it includes what music de facto does, as well as what it should do) is not formulated explicitly within some elaborate theory. It was only a part of a then widespread way of thinking about music, and about art in general. Hanslick does not go into details of such thinking (which he considers to be very vague), but rather dismisses it completely.

Hanslick first rejects the normative component of the definition: he claims that beauty has no purpose at all, for beauty is mere form, i.e. a shape in which something appears, which by itself has no purpose. ${ }^{4}$ Although something that is beautiful can be applied to many purposes, and even used solely for a specific purpose, this purpose is not what makes the thing beautiful, i.e. the thing is not beautiful because some intention or purpose is realized..$^{5}$ Beauty, in Hanslick's view, is in the thing that is beautiful, and which remains beautiful „even if no feelings are aroused and even if it be neither perceived nor thought." 6

Stating that the arousal of emotions is what defines music means that arousing human emotions is specific for music, and differentiates it from other arts. Hanslick's objection is simple: emotions are aroused not only by other arts, but also by various non-aesthetical preoccupations (Hanslick's examples are rhetoric and religious fervour), and by everyday events as well. ${ }^{7}$ Hanslick does not see how can in principle music be differentiated from other arts by arousal of emotions. ${ }^{8}$

Furthermore, although works of arts do stand in some kind of relation to our emotions, none of them stands with in an exclusive relation to emotions. In other words, art is not exhausted in its connection with human emotions. ${ }^{9}$ Is it only one of many aspects of music, and therefore, insufficient for defining it.

4 It is easier to understand this statement in connection with the explanations Hanslick gives later in the text, when he compares artistic and natural beauty or when he compares music with arabesque and kaleidoscope: the beauty in all those examples is in the form itself, independent of what is formed or shaped. This means that beautiful objects are beautiful due to their formal properties, that is, the properties accessible by sensory perception. In the case of both artistic and non-artistic objects, beauty concerns the order or harmony of the parts of the object, while any possible purpose of the object does not affect its beauty.

5 See OMB, p. 3, OML, p. 42. Hanslick will explain what does make a beautiful thing beautiful in the positive thesis.

$6 \quad$ Ibid.

7 See OMB, p. 5, OML, p. 45.

8 One possible answer that Hanslick mentions is that the difference is in the manner of arousal: that music arouses emotions directly, as opposed to other arts where the arousal is mediated by conceptual content. However, Hanslick objects to this by explaining that the arousal caused by listening to music is also multiply mediated starting with sensations, imagination and so on. Feeling is nothing more than a secondary effect of music - as well as of other arts - see OMB, p. 4, 5-6, OML, p. 43, 45-46. Music does stand out in its effect on the feelings because it affects us more rapidly and intensely than other arts. Hanslick demonstrates further in the treatise that this difference is physiologically conditioned and does not arise from the artistic aspect of music, but rather from its material that is in a certain relation with our physiological organisation. Therefore, this effect cannot be something that is artistically specific of music - see OMB, p. 50-1, OML, p. 118-9.

9 See OMB, p. 6, OML, p. 46. 
Hanslick proposes additional reasons against such defining, which demonstrate how uncertain and variable the relation between music and the emotions aroused by it is. Firstly, our thoughts and emotions elicited by music are often guided by titles, texts and other merely incidental associations of ideas (especially in church, military and theatre music), which we often wrongly ascribe to the music itself. Besides, the relation between an art of music and our mood changes is also determined by our changing musical experiences and impressions. Hanslick asserts that nowadays we can scarcely understand how some earlier generations of music listeners could regard some particular music sequence as a precisely corresponding expression (Ausdruck) of a particular feeling. He supports this assertion by citing "the extraordinary difference between the reactions of Mozart's, Beethoven's and Weber's contemporaries to their compositions in different historical periods. He concludes that the way feelings will be aroused by music depends on the circumstances of each particular instance. ${ }^{10}$

After this, Hanslick makes an additional remark, that throughout this variation in the reactions to music, the musical value of the works themselves remains unaltered. This leads Hanslick to conclude that the effect of music upon feelings possesses neither the necessity nor the constancy nor the exclusiveness (in relation to the value of the musical work) which a phenomenon would have to exhibit in order for us to base the criteria for work's value on it. Thus, Hanslick rejects not only the view that the aroused emotions define music, but also the view that the arousal of emotions can be the criteria for value (i.e. aesthetical principles) of musical works.

\section{The second role: emotions as the content (which should be) represented by music}

From the differences among human senses, to which the arts are bound, follow the fundamental differences in the way the various arts shape their products (i.e. the difference of their forms), and from that, further, follows the diversity of content among the arts. Every particular art has its own range of ideas which it represents in its own form of expression, with its own means of expression (Ausdrucksmitteln), e.g., tones, words, colours, etc. Hanslick claims that an artwork embodies a certain idea as beauty in sensuous appearance. ${ }^{11}$ In other words, by these means of expression an artist externalizes or embodies an artistic idea in such a way that the idea appears to our senses as something beautiful, as a beautiful form.

The view that Hanslick rejects is the belief that the whole range of human feelings is the content of music, that these feelings are the ideas music acoustically

10 See OMB, p. 6-7, OML, p. 47-8. Hanslick also notes that, while Mozart's music was described by his contemporaries as passionate and struggling as opposed to the tranquillity and wholesomeness of Haydn's works, the same comparison was made just a few decades later between Mozart and Beethoven.

11 See OMB, p. 8, OML, p. 55. 
embodies in shaping its works. According to this view, tones and their artistically shaped relations would be mere raw material, the means of expression by which the artist represents human feelings. Hence, what we enjoy in music and what has an effect on us is not the melody and the harmony we are listening to, but the feelings they signify (bedeuten). ${ }^{12}$

Hanslick's statement, which will be under many attacks in later philosophical works, is the claim that music is not able to represent definite feelings. ${ }^{13}$ In order to demonstrate that, he proposes the following arguments:

In the first argument, Hanslick claims that what is specific for a feeling, what renders it a definite feeling, and hence is the criterion by which we are able to extricate and discern it from other feelings, is its conceptual content, a number of conceptions and judgments (Vorstellungen und Urteile) which are associated to the concept of that feeling. Therefore, e.g., „the feeling of hope cannot be separated from the representation of a future happy state which we compare with the present," or "love cannot be thought without the representation of a beloved person, without desire and striving after felicity," etc. ${ }^{14}$ Without this conceptual, cognitive apparatus, all that remains is an unspecific stirring, a general state of well-being or distress, and the intensity and oscillations which are not specific for the feeling (because different feelings can have the same intensity and oscillations, and, also, the same feeling can vary in its intensity). It is not clear how pure instrumental music could be able to convey or reproduce concepts or representations, for they are not within the scope of music. ${ }^{15}$ Since the specification of the feelings cannot be separated from their conceptual content, and since music cannot reproduce (wiedergeben) concepts, Hanslick concludes that music cannot represent specific feelings. ${ }^{16}$

The second argument states that the only aspect of feelings music is capable of representing, since it is the aspect they both share, is the dynamic aspect, the dynamic flow of experiencing a feeling. Music can imitate (nachbilden) only the motion of a physical process, the characteristic way of motion. Motion is something both music and feelings share, but it is only one aspect of feeling, which, as said already, can be shared by different feelings, and also vary in one feeling, since the same feeling does not always have the same dynamics. Hence, dynamics cannot be specific for a feeling. ${ }^{17}$ Therefore, since the only aspect of feelings which music can represent is not specific for any feeling, it follows that music cannot represent specific feelings.

The argument I propose as the third one emphasizes that the ideas of specific feelings cannot appear or be embodied in instrumental music because

12 See OMB, p. 8-9, OML, p. 56.

13 See OMB, p. 9, OML, p. 56, VMS, p. 22: „Die Darstellung eines bestimmten Gefühls oder Affektes liegt gar nicht in dem eigenen Vermögen der Tonkunst.“

14 See OMB, p. 9, OML, p. 57.

15 See OMB, p. 10, OML, p. 58.

16 See OMB, p. 9, OML, p. 57-8.

17 See OMB, p. 11, OML, p. 60-1. 
there is no necessary (notwendiger) connection between those ideas and certain combinations of musical tones. I take this to mean that there is nothing in the tones themselves and in their combinations which would necessarily or unambiguously refer to feelings. ${ }^{18}$ This was just a statement Hanslick mentioned within the argument concerning the dynamics. However, I identify it as a separate argument because I take it as implicitly stating that, because of lacking the so-called "necessary" connections, music cannot present its tone structures as structures relating to feelings. It cannot present its dynamic flow as the flow of a feeling. ${ }^{19}$ Therefore, even though music can successfully imitate certain aspects of feelings, it has no means to connect those aspects unambiguously with a feeling. In other words, the connection between music and feelings always stays in our open interpretations.

In the forth argument, Hanslick appeals to the empirical testing of the thesis that music can represent feelings. However, I consider that, at the same time, he points out a certain weakness of the emotional aesthetics and all similar theories, and that is the justification for ascribing any particular emotional content to an artwork. Namely, says Hanslick, if someone considers that music indeed can represent feelings, let him try to demonstrate, with arguments, which feeling constitutes the content of an artwork. ${ }^{20}$ If we should ask the listeners of the most popular musical works at the time, from Mozart to Chopin, to name the feeling they consider to be the content of the work, there would, in Hanslick's opinion, be different answers (e.g. love, yearning, piety). ${ }^{21}$ As well as there could be no demonstration of why any of the answers would be correct, nobody could refute any of them, either. ${ }^{22}$ Therefore, there is not only the discrepancy about which feeling is represented by some musical work, the fact is that we do not even have at our disposal the means - the reasons, by which we could choose the right answer to what is the content of the work. ${ }^{23}$

In the fifth argument, Hanslick turns to the representation of feelings in vocal music as well. First of all, it should be noted that for Hanslick, the relation

18 Ibid.

19 Malcolm Budd later explicated this argument (See Malcolm Budd, Music and the Emotions: The Philosophical Theories, London, 1985. p. 24.), and Steven Davies took this explication over as an addition to the rest of Hanslick's arguments which refutes all attempts at crossing the gap between music and the emotions (see Stephen Davies, Musical Meaning and Expression, Ithaca NY, 1994. p. 217-9.).

20 See OMB, p. 12, OML, p. 62-3.

21 Earlier in the treatise, Hanslick mentions different documented descriptions of the same compositions and notes that the listeners have had different opinions about which sequence of tones were adequate expressions for which feeling. See OMB, p. 6-7, OML, p. 47-8.

22 See OMB, p. 14, OML, p. 65.

23 See OMB, p. 14, OML, p. 65-6. The argument supposes Hanslick's sense of representation as exposition of a content in a manifest manner. Thus it is understandable that Hanslick does not see how we can designate something as what an art represents, when the it is the very dubious and ambiguous element of that art, perpetually subject to debate. Also, this lack of reasons (which would support the ascription of any emotional content to a composition) is connected to the previous argument, that is, with the lack of the necessary connection between tone groups and definite feelings. 
between music and the text in a vocal composition is such that music alone with its assets has the power only to enhance, revive, or colour the content of the text. But what is represented in a vocal work is determined by the text, not by the music. ${ }^{24}$ Hanslick claims that music is not determined enough so that it could represent feelings in a determinant way, thus the same melody might just as appropriately be played along some words with a very different, even the opposite meaning. Hanslick substantiates this with a number of examples. Namely, concerning Gluck's opera Orpheus and Eurydice, a contemporary of Gluck remarked that, in the Orpheus aria (which moved many of the listeners to tears), "one could just as well or, indeed, much more faithfully set the opposite words to the same tune” (that instead of „I lost my Eurydice," the words say „I found my Eurydice”). ${ }^{25}$ Hanslick himself remarks in addition to this that „music certainly possesses far more specific tones for the expression of passionate grief" 26 and emphasizes that he picked this example intentionally, first, because Gluck „has been atributed the greatest exactitude in dramatic expression and, second, because over the years so many people have admired in this melody the feeling of intense grief which it expresses in conjunction with those words." ${ }^{27}$

What was true for these smaller parts of musical works, Hanslick continues, applies to the whole compositions as well. Many whole vocal compositions have used different texts with the same music. Hanslick lists a number of examples: ouverture to Mozart's The Magic Flute is often performed as a vocal quartet of quarrelsome Jewish shopkeepers, and Mozart's music, with not a single note altered, suits the low-comedy words surprisingly well; in many German provincial churches sentimental love songs are performed during the celebration of the Mass; in Italian churches, also, popular wordly tunes of Rossini, Bellini, Donizetti and Verdi are played, and they do not at all disturb the devotions of parishioners, but, on the contrary, inspire them even more; many of the most famous pieces in Hendel's Messiah, including the ones most admired for their godly sentiments, are taken from the secular and mainly erotic duets which Handel composed earlier; the madrigal-like pieces in J. S. Bach's Christmas Oratorio were transcribed from altogether dissimilar secular cantatas; Gluck, who is considered to has achieved great dramatic truth in his music only by fitting each note precisely to the specific situation, in Armida transcribed five pieces from his earlier Italian operas. ${ }^{28}$ These examples lead Hanslick to conclude that if music itself were capable of representing a specific feeling, say, devotion,

24 See OMB, p. 16, OML, p. 67.

25 See OMB, p. 17, OML, p. 67-8.

26 See OMB, p. 18, OML, p. 69. I believe that this passage shows Hanslick's attitude toward the issue of music's expressiveness. It is clear in the passage that he thinks that melodies and other musical elements or passages can be suitable for the expression of feelings, but not in a way in which they would be tied to the expression of only one particular feeling. The same melody could express several different, even disparate feelings. In other words, Hanslick takes musical elements to be indefinitely expressive.

27 Ibid.

28 See OMB, p. 18-19, OML, p. 69-72. 
as its content, such a quid pro quo would be as impossible as if the preacher could substitute his sermon with reciting a novel or a page of parliamentary transactions. ${ }^{29}$

\section{The beauty and the representation of feelings in music}

After the exposition of the arguments which demonstrate that music cannot represent specific feelings, Hanslick further considers the possibility that the representation of feelings is an ideal for music which it can never achieve, but which it can and should strive to approach. ${ }^{30}$ This would mean that the beauty of music resides in the representation of feelings in the degree in which such representation is possible. Hanslick proposes arguments which refute such a possibility by taking the counterfactual point of view: let us imagine that musical representation of definit feelings is possible so we could show that the degree of exactitude with which music represents them does not coincide with the beauty of the artwork. ${ }^{31}$ Hanslick tries this fiction with vocal and not instrumental music, since instrumental music by itself automatically excludes the possibility of identifying definite feelings, whereas in vocal music the feelings allegedly represented are indicated by the text. The words in vocal music determine what is being represented and what is being revived by music in tonal motion. ${ }^{32}$ If we suppose that musical representation of feelings is possible and that the exactitude of the representation coincides with the beauty of the artwork, then we should consider those compositions which accomplish that task most specifically (bestimmtesten) the most beautiful. ${ }^{33}$ However, firstly, everyone knows of musical pieces we evaluate as works of utmost beauty which have no such content (e.g. the preludes and fugues of J. S. Bach). Secondly, there are, opposed to these, vocal compositions which try to portray a specific feeling (within the limits just explained) and in which truth of portrayal has precedence over any other principle, and, yet, which do not possess a great degree of beauty. The third argument against the same thesis states that in a vocal composition we can make many small alterations, which, without weakening the expression

29 See OMB, p. 18-19, OML, p. 70.

30 See OMB, p. 21, OML, p. 74.

31 Ibid.

32 See OMB, p. 21-2, OML, p. 75. Contemporary interpreters consider this transition to the examples of vocal music as a problem for Hanslick, so I will try to further explicate this passage and reconstruct what might have been Hanslick's motivation for making that choice. Namely, so far Hanslick was speaking solely about the instrumental music (since, as he says, we may only say that music can do of what instrumental music, with no help from non-musical means, can do), and he was demonstrating that it cannot represent definite feelings. Now, for the sake of the argument, he supposes that the music in vocal pieces can represent feelings (that is, he imagines that representing the dynamic aspect is sufficient for the representation of definite feelings) which are the content of the text. The text enables us to identify what is being represented by the music and we can thus judge to what extent was the representation successful. 
of feeling, yet immediately destroy the beauty of musical themes. This would be impossible if the beauty consisted in the exactitude of expression of feelings. ${ }^{34}$ Therefore, we can make changes in one aspect without affecting the other.

The supposed thesis cannot explain this mismatch and Hanslick concludes that we cannot identify the beauty in music with the exactitude of representation of feelings. They are separate principles, since musical beauty demands an autonomous content, whereas the representation subordinates the beauty to non-musical factors. ${ }^{35}$ The principle of autonomous beauty and the principle of representation any non-musical content are, therefore, two separate principles. In addition, in recitative we have separately the principle of musical beauty and the declamatory principle (adjusting the music to sound like speech), in opera the well-known struggle between between the principle of dramatic realism and that of musical beauty, just as in dance and ballet there is a struggle between the dramatic principle and the principle of plastic and rhythmic beauty. ${ }^{36}$ In all these art forms, we can see different principles and each of them has its own demands, which go in different directions. By this Hanslick tries to sort out the specifically musical (or formal) principle from all the other principles we might equate it with. The musical principle is directed towards forming autonomous musical beauty.

Hanslick further tries to explain what beauty in music really is and what it consists of if not in representation or arousal of feelings. This constitutes the socalled positive thesis.

\section{Formalistic definition of the beauty in music}

Hanslick defines the beauty in music as specifically musical kind of beauty: beauty which, irrespective of some non-musical content, consists solely in tones and their artistic combination. ${ }^{37}$ Hanslick's formalism is apparent in that he considers the content of music to be the form of music itself. In addition, he bases the criterion of beauty on the form of music, which I will elaborate bellow. Namely, the material (Material) out of which the composer creates - the substance of music - is tones, with their latent possibilities for melodic, harmonic and rhythmic variety. The content, i.e. what is expressed by means of this tonematerial, is musical ideas, or tone-ideas, not some non-musical ideas concerning, say, feelings, which would then have to be translated to the tone-language. ${ }^{38}$ The form, consisting of tone structures of the composition, is a realized artistic idea, or the embodiment of the content. The relation between content and form is not,

34 See OMB, p. 26, OML, p. 81. At this point Hanslick speaks of representation and expression interchangeably, because his focus is on showing the difference between musical and any other non-musical principle (which involves both representation and expression of feelings).

See OMB, p. 22, OML, p. 76.

36 See OMB, p. 22-3, OML, p. 77-8.

37 See OMB, p. 27-8, OML, p. 81-3.

38 See OMB, p. 28, OML, p. 83-4. 
as is typically thought, the translation of an idea into some medium disparate from it. It is, rather, a relation of gradual elaboration, detailed development to the final form. ${ }^{39}$ Since tone-ideas - ideal tone structures - are the content of music, the content of a composition is inseparable from its form (because the form also consists in tone structures). ${ }^{40}$ In other words, the tone structures we hear in a composition express just ideas of those same tone structures, because, as Hanslick says, "music speaks not merely by means of tones, it speaks only tones." ${ }^{41}$ All this is implicitly contained in Hanslick's definition of the content of music as "tonally moving forms." 42 I would add that in this definition Hanslick also succinctly included the time dimension of music: music forms do not stand motionless, they move through time by the successive sounding of tones they are made of, or, in Hanslick's words, they come into being ,in continuous selfformation before our eyes." 43 This tone motion does not convey any other, nonmusical content as is ordinarily believed, and the beauty in music is the beauty of these tone-forms themselves. In order to make his point clearer, Hanslick gives examples of such purely formal beauty, beauty with no content from the outside: arabesque, kaleidoscope, and later he adds works of architecture, dance, human body and natural beauty such as a landscape, a leaf or a flower. All these examples, Hanslick notes, also possess some kind of primitive beauty of outline and colour, setting outside any expression or non-musical content. Hence, formal aspects of all of them rest on the same basis, but unlike others, with the exception of architecture works, musical works are produced by artistic endeavors and express the ideas of the artist. ${ }^{44}$ For that reason, we have a different relation to formal beauty in music then to the beauty of non-artistic objects. This leads us to, in my opinion, the key point of Hanslick's view on music and musical beauty, which is completely neglected in many, especially contemporary interpretations. Namely, musical beauty is, for Hanslick, defined dually: first, concerning only our senses, as acoustical beauty in analogy with just mentioned visual examples,

39 See OMB, p. 28, OML, p. 83-4: "A musical idea turns up in the rough in the composer's imagination; it takes shape progressively, like a crystal, until imperceptibly the form of the completed product stands before him in its main outlines."

40 See OMB, p. 80, OML, p. 171: "But in music we see content and form, material and configuration, image and idea, fused in an obscure, inseparable unity." and "In music there is no content as opposed to form, because music has no form other than the content."

41 See OMB, p. 8, OML, p. 55, and OMB, p. 78, OML, p. 167. Also: Music says everything the composer wanted to say - see OMB, p. 37-8, OML, p. 100.

42 „Der Inhalt der Musik sind tönend bewegte Formen“ - see OMB, p. 29, 101-2, OML, p. 84. The literal translation would be that the content of music are soundingly moving forms. However, it should be noted that Hanslick consistently throughout the treatise uses the word "ton" in the sense of tone, and not sound (for this he uses the term "Klang"), see OMB, p. 102. Therefore, soundingly is not an entirely adequate translation of Hanslick's tönend, since it omits the difference between a tone and a sound. Alternatively, the content of music could be defined as "forms moved by the sounding of tones," or, simply, as "tonally moving forms," which makes Payzant's final choice.

43 OMB, p. 29, OML, p. 84: “(...) in fortwährender Selbstbildung vor unsern Augen entstehend.”

44 See OMB, p. 29, OML, p. 84-6. 
and, second, concerning the artistic aspect and the art of shaping tone material, as artistic value of embodied musical ideas, or externalized tone forms.

The first component - sensuous beauty of tone forms - is determined by certain fundamental laws of nature, which govern the external manifestations of sound and interrelations of all musical elements, and also the human organism (e.g. which frequencies of sound we hear as pleasant, what we hear as harmony and what as disharmony of tones etc.). These (negative, as Hanslick names them) regularities, which are inherent in the tonal system due to the laws of nature, are the basis for further capacity of tones for entering into the so-called positive content of beauty, which in fact constitutes the artistic aspect of musical beauty. ${ }^{45}$

The realization of artistic ideas is achieved not through linking tones mechanically into a series, but by spontaneous work of the composer upon the tone material, the artistic structuring of tone relationships. The artistic value of the ideas thus realized is the second component of musical beauty. Hanslick does not give details about what exactly makes a composition artistically successful, but only emphasizes that it always concerns the form of the composition. Artistic ideas and artistic treatment of the material are immanent in the form: tone structures we hear in music are realized artistic ideas themselves, and in listening to the tones, we are able to follow the artistic acts of the composer, which can be successful or unsuccessful, and thus we can evaluate them in terms of their artistic value. ${ }^{46}$

Musical beauty, therefore, consists in the artistic value and acoustic beauty of a formed (or, realized) tone idea ${ }^{47}$ This dual definition of beauty is reflected also in Hanslick's claim that we notice musical beauty (it „makes itself known in aesthetical awareness") immediately, by itself, through the harmony of its parts, and without reference to any factor external to the harmonious form of music, 48 but, unlike contemplating the beauty of non-artistic objects, in listening to music we do not stay on the surface of its sensuous aspect. Artistic beauty is designed by a creative mind, and we, thus, in the structure of the composition and in the beauty of that structure, consciously follow the ideas, or the artistic acts of its creator. ${ }^{49}$

45 See OMB, p. 30-1, OML, p. 88. Hanslick already noted that specifically musical beauty must not be understood as simply acoustic beauty (which musical beauty often contains, but cannot be reduced to), nor as an ear-pleasing play of tones, see OMB, p. 30, OML, p. 87. It is clear that he does not take the term beautiful in the usual sense, and that by it Hanslick understands not only the sensuous, but also the artistic aspect of music.

46 See OMB, p. 31, OML, p. 88-9.

47 Hanslick's including of acoustical pleasure into his understanding of beauty is also evident when he cites Grillparzer's comments on the ugly, or unbeautiful, where he claims that, as opposed to poetry, music cannot make use of the ugly in its works, since the impression of music is received and enjoyed directly from sensation, so the understanding's approval comes too late to compensate for the intrusion of the ugly. "Hence Shakespeare can go all the way to the hideous, but Mozart has to stay within the limits of the beautiful." - See fn 18, OMB, p. 31, OML, p. 186.

48 See OMB, p. 32, OML, p. 90.

49 See OMB, p. 60, OML, p. 133-4: The second component, or the „ideal content,“ as Hanslick says, can be understood only by the cultivated listeners, while the first component is characteristic for the pleasure of the naive audience that exists in every art. Hanslick 


\section{Describing music in terms relating to emotions}

The formalistic definition exposed in previous passage leads us to the next significant point of Hanslick's view on music. Namely, when we speak about music, we describe it in various ways, but mostly by using terms that relate to non-musical phenomena, especially feelings. Hanslick was not only well aware of this, but was often describing music in that way himself. In addition, he explained why we have the tendency to use these terms when describing music, and why this phenomenon does not have the significance we are inclined to ascribe to it.

Firstly, Hanslick claims that the content of music cannot be expressed in words or subsumed under concepts: music has sense and logic, but musical sense and musical logic. Music is „a kind of language we speak and understand yet cannot translate." 50 Therefore, it is extraordinarily difficult to describe this specifically musical: purely musical content and specifically musical beauty. Since music has no prototype in nature to imitate, and expresses no conceptual content, Hanslick claims that it can be talked about only in technical definitions or figuratively - „What in every other art is still description is in music already metaphor." 51 Thus we say, for example, that one particular musical conception is, taken by itself, witty, while another is banal, or sounds impressive, or insipid. Hanslick emphasizes that we quite rightly describe a musical theme as majestic, graceful, tender, dull, hackneyed, but all these expressions describe the musical character of the theme. ${ }^{52}$ This means that by describing music in such ways, we are not talking about the feelings of the composer, or the feelings that would be the content of the theme. We are talking about the impression the combination of musical factors used in that theme makes. ${ }^{53}$ In order to describe musical characters, we often choose terms from the vocabulary of our emotional life, such as arrogant, peevish, tender, spirited, yearning. However, we can also take our descriptions from other realms of phenomena and speak of fragrant, vernal, hazy, chilly music. Feelings are thus, for the description of musical characters, only one source among others which offer similarities (Ähnlichkeit). ${ }^{54}$ Thus,

consideres both of these approaches as legitimate, aesthetical approaches (since the listeners direct their attention on the artwork and its details), as opposed to the so-called pathological reception which involves a passive enjoyment only in the general impression of the piece and in the feelings wafting through it.

50 See OMB, p. 30, OML, p. 87.

51 OMB, p. 30, OML, p. 86.

52 See OMB, p. 32, OML, p. 90.

53 See OMB, p. 32-3, OML, p. 91-2. If the impressions and descriptions of musical compositions were uniform, then, even if the descriptions were merely figurative, it might indicate an objective connection between the tone groups and non-musical phenomena. However, Hanslick has already shown that the impression of the composition (and hence the description as well) in some way or another is, even in the same listener dependent on the previous musical experiences, on non-musical associations (titles, programs, etc.), as well as on various other factors. Therefore, describing music in the mentioned way by all odds is not uniform, but to a great extent diverse and variable.

54 See OMB, p. 32, OML, p. 90-1. It seems that this passage is somewhat ambiguous since Hanslick does not explain what he means by the term similarities. Budd is inclined to understand it as 
Hanslick believes that describing music in terms relating to non-musical phenomena does not imply the existence of some objective relation between music and those phenomena, whether it is feelings, weather conditions, or phenomena of some other realm. It is proper to use such descriptions, which we even cannot do without, provided we never lose sight of of the fact that we are using them only figuratively. We may say, for instance, that a musical theme sounds gloomy, but we should take care not to say it portrays arrogance, or that it is an expression of the gloomy feelings in the composer etc. ${ }^{55}$ Such descriptions indicate the effect a composition has due to its musical factors, or the combination of musical elements in it. In addition, Hanslick notes that since the individual musical elements already possess their own characteristic expressiveness, the predominant characteristics of the composer, such as sentimentality, energy, serenity etc. will be revealed through his „partiality toward certain tonalities, rhythms, transitions, in accordance with the prevailing impulse which the music is able to reproduce." 56 However, Hanslick stresses in another passage that, although there is, of course, a connection between the character of every piece of music and the character of its author, this connection, firstly, in not visible to the aesthetician, and, secondly, the comparison of the characters of musical pieces and their authors is infinitely complicated and will be more prone to fallacies, the stricter the causal connection it seeks to establish. ${ }^{57}$

I consider it obvious, especially in the last passage, that Hanslick did not support the radical position which is usually ascribed to him. Moreover, his view on the relation between music and emotions is compatible with the views of contemporary authors who claim to disagree with him. I believe that the key difference between Hanslick's and their views is actually the difference in emphasis. Namely, in the treatise On the musically beautiful, Hanslick's main intention was to refute the claims of those who were, in his opinion, actively

dynamic similarity since dynamic is the only aspect that Hanslick says is common for music and feelings - see Budd, op. cit, p. 31. However, I wish to offer an explanation according to which Hanslick does not presuppose a real similarity between music and other phenomena: a common aspect such as dynamics, which enables us to describe music by using words in their literal meaning (rapid, slowly, etc.). Hanslick himself says that when we describe music, we mostly use figurative speech. I, however, take this figurative use to be a use of the words in what Wittgenstein would call their secondary meaning - see Ludwig Wittgentstein, Philosophical investigations, Basil Blackwell Ltd 1958, p. 216. This kind of use is exemplified when we use the term "warm" to describe sounds (e.g. the sound of flute), colours (yellow), even smells (the smell of vanilla). The term "warm" is clearly not used in its basic - literal meaning, but we also would not be inclined to say this is a metaphor which could somehow be unraveled: what we are trying to say by using these kinds of descriptions we cannot say in any other way but with that exact term. Likewise, music cannot literally be melancholic, fragrant, or chilly, but neither can those descriptions be reduced to the descriptions containing some other terms with no loss of sense. This is consistent with Hanslick's statement in the same passage that we cannot do without these descriptions. I believe that this is the way Hanslick implicitly understands descriptions of music by using terms concerning emotions, as well as weather conditions and other kinds of phenomena. 
misleading the listeners, who then would not be able to recognize the most essential aspect of music - the music itself, or the art of shaping tone material. Hence, Hanslick displaces emotions aside: we should focus on music, and not the emotions, regardless of the way they relate to music. Contemporary authors, on the other hand, emphasize the relation between music (regardless of how it is defined) and the emotions, and consider the importance of emotions in our reception of music. Contemporary authors do not notice that unspecific emotional expressiveness of music is indeed compatible with the main intention of Hanslick's treatise. Here I shall end my interpretation of Hanslick's view. Further, I will expose the interpretations of the same treatise, made by several most influential contemporary music aestheticians, and then try to demonstrate why those interpretations should be refuted.

\section{Contemporary interpretations of Hanslick's view}

Contemporary authors mostly write about the negative part of Hanslick's treatise, and interpret only his arguments against the so-called emotional aesthetics. I believe that their reconstruction of Hanslick's arguments and conclusions is incorrect, in interpreting both the arguments alone, as well as the relations between the arguments and the conclusions. I shall not go into every detail of their interpretations, but, rather, try to prove my thesis on several points I consider most relevant.

According to Malcolm Budd, Hanslick tries to establish three negative conclusions about the relationship between music and the emotions. The first one states that it is impossible for any definite emotion to be represented by a piece of music, and, hence, that the musical value, the "beauty", of a piece of music is never dependent on representing emotions by music. ${ }^{58}$

Budd only presents one of many Hanslick's arguments for this conclusion the conceptual content argument. Budd reconstructs this argument as following: music cannot represent thoughts, and definite emotions contain or involve thoughts; therefore, music cannot represent definite emotions. ${ }^{59}$ Budd mentions that, in this argument, Hanslick stresses that definite emotions are distinguished from each other only by the thoughts they contain, that every other feature of an emotion can be shared with others. However, it seems that Budd takes what is contained in the emotion as the key point of the argument. ${ }^{60}$ Accordingly, he takes the argument to depend on the theory of emotions we adopt, on how we understand the notion of representation, on the idea of one phenomenon containing or involving the other, and also upon the validity of the principle that if one thing involves another thing then in order for something to represent the first thing it must represent the second thing. ${ }^{61} \mathrm{I}$ believe that, by putting

58 See Budd, op. cit, p. 20 Budd takes Hanslick's musically beautiful to be equivalent to the value of a musical piece.

59 Ibid, p. 21.

60 Ibid, p. 22.

61 Ibid, p. 21-4. 
emphasis on what emotions contain instead on how they are distinguished from each other, Budd made this argument more complicated than it is, and rendered it dependent upon the considerations upon which, it seems to me, it does not depend. Contemporary authors use a different view on emotions to try to examine or refute this argument. Hanslick, however, does not engage in any serious theoretical consideration concerning what emotions are exactly, what they involve etc. He supposes, on an intuitive level, what may be specific for particular emotions, and how they can be distinguished from each other (among other, by the listeners whom music would represent emotions to), and what of all that can music represent, or imitate. Although it may seem that this argument would have been more convincing if it had been grounded on a theory of emotions, I believe that its strength actually lies in the fact that it is formulated in this way, more on an intuitive than on a theoretical level. I shall try to demonstrate this point further in the paper, in the exposition of Jenefer Robinson's interpretation of the same argument.

Budd then presents three arguments for the first main conclusion - that the value of a composition would not depend upon their being accurate representations of definite emotions, even if such representation were possible. ${ }^{62}$

The first argument is that some valuable pieces of music do not represent a definite feeling. Budd's objection to this argument is that it counts only against the stronger view that each valuable work represents definite emotions and its musical value is in some way dependent upon this function. It leaves untouched the view that the value of some music pieces is a matter of music's representing definite emotions. However, it is Budd's formulation of the conclusion that changes the point of the argument, and renders it unsuccessful. Hanslick does not, in fact, speak about the relation of dependence, but about a relation of congruence between musical beauty and the representation of feelings, and this is supported by the text of his treatise. ${ }^{63}$ When the conclusion is formulated so that it states that musical beauty and the exactitude of the representation of feelings do not coincide, and that the former does not consist in the latter, the argument becomes successful.

The second argument concerns the alleged inverse proportion between the beauty of music and the exactitude of the representation of feelings by music. In Budd's version, Hanslick claims that vocal music, as it represents feelings more perfectly (in the sense of succeeding to represent them), becomes musically less beautiful. Since this turns to contradict Hanslick's own belief that such representation is impossible, Budd tries to save the argument by interpreting

62 Ibid, p. 25.

63 See OMB, p. 21, OML, p. 74: "Even if it were possible for feelings to be represented by music, the degree of beauty in the music would not correspond (kongruieren) to the degree of exactitude with which the music represented them. Let us for the moment, however, suppose that it [the representation of feelings] is possible and consider the practical consequences." The arguments that follow are, in fact, designed to show the incongruity of musical beauty with the representation of feelings, not the independence from it. Budd, on the other hand, does not leave a reference for his formulation of the conclusion, but it is clear that he refers to the same passage. 
Hanslick as saying that as the words represent definite feelings more accurately, so the music becomes less beautiful. ${ }^{64}$ This formulation does indeed avoid creating a contradiction, but, unfortunately, does not make much sense either. Budd actually does not notice that Hanslick does not speak about the degree to which music succeeds in representing a feeling, but rather about the degree to which music was tailored to representation, or adjusted so that it fits some non-musical idea, and how much it was, on the other hand, composed only with musical beauty in mind. I consider this to be inverse proportion Hanslick mentions. On top of that, this was not even an argument that was supposed to prove anything, but rather a passing comment about vocal pieces that were mostly dedicated to the musical portrayal of feelings. ${ }^{65}$

The last argument for the same conclusion concerns the slight alterations that can be made to the music in any song, which do not affect the accuracy of the representation of feelings at all, but which destroy the beauty of the theme. According to Budd, all that Hanslick intends is merely that the reference made by the words of the song to the particular emotions will always remain, while the overall beauty of the piece is affected. This does not succeed in supporting what Budd takes to be Hanslick's thesis: that the value of a composition never depends on the representation of emotions by music. ${ }^{66}$ In my interpretation, on the other hand, this actually is a successful argument, since it shows that it is possible that the accuracy of musical expression of the content of the text - within the limits of representing the dynamic aspect - remains the same, while the beauty of the music is changed. This does support what I take to be Hanslick's conclusion: that musical beauty of a composition and the accuracy of representation (or, as in this case, expression) are not the same thing. This interpretation not only renders Hanslick's argumentation far more sensible, but also accords more with other Hanslick's claims. ${ }^{67}$

Hanslick's second conclusion concerns the arousal of emotions. According to Budd's interpretation, Hanslick here rejects the arousal of emotions as an aesthetically relevant relation between music and emotions. Budd's objection is that Hanslick fails to recognize the distinction between the so-called musical and extra-musical emotions, that is, the emotions which have the music as their object (e.g. being impressed by a composition), and emotions which have an object

64 See Budd, op. cit, p. 26.

65 See OMB, p. 22, OML, p. 76: “(...) there are vocal compositions which try to portray a specific feeling with the greatest accuracy, within the limits we have just explained, and in which truth of portrayal has precedence over any other principle. Upon closer examination, the outcome is that even the most relentless fitting of music to feeling in such a musical portrait generally succeeds in inverse proportion to the autonomous beauty of the music (...)"

66 See Budd, op. cit, p. 26-7.

67 See OMB, p. 21-22, OML, p. 75. When discussing this very group of arguments, Hanslick mentions that "music has the power to animate the object, to comment, and to bestow upon it in greater or lesser degree the expression of individual subjectivity. It does this as far as possible through the characteristics of motion and through exploitation of the inherently symbolic aspects of tones." Hanslick's counterfactual approach in these arguments consists in supposing that dynamic representation is sufficient for musical representation of a definite feeling. 
aside from music (e.g. being sad over some event while listening to music). Budd considers it unnecessary to deny, as Hanslick does, that an extra-musical emotion can be experienced in an aesthetic response to music in order to maintain the doctrine of the specifically musical nature of the beauty of music. ${ }^{68} \mathrm{I}$ believe that here also Budd misses some Hanslick's statements which clearly show that he did recognize the existence of the so-called musical emotions. ${ }^{69}$ This is most obvious in the chapter in which he explains the difference between an aesthetic and non-aesthetic reception of music. Hanslick rejects as aesthetically irrelevant only those emotions that are aroused in passive listening to music, during which we do not focus on the music itself. ${ }^{70}$

Budd believes that the third way it might be thought that music can be related to an emotion in an aesthetically significant manner is by music's being expressive of an emotion or by music's possessing an emotional quality. ${ }^{71}$ Denying that describing music as proud, longing, etc. implies an aesthetically relevant relation between music and the emotions is, according to Budd, Hanslick's third negative conclusion. Hanslick allegedly tries to defend this conclusion by stating that descriptions of music that contain emotional terms are either improper or deletable. ${ }^{72}$ Budd then explains why Hanslick is mistaken to claim that emotional terms are deletable when they are used this way, ${ }^{73}$ and on top of that stresses that it is unclear how this figurative use of words is supposed to work, for the only analogy Hanslick allows between an emotion and a piece of music is their dynamic features, and yet neither feature that Hanslick mentions as an example is not a dynamic feature (longing, fresh, etc.). ${ }^{74} \mathrm{I}$ take that the mistake in Budd's interpretation is in misunderstanding Hanslick's statement that, when we describe music, just as we use the terms concerning emotions,

68 See Budd, op. cit, p. 27, 30-1.

69 For example: "Far be it from us to want to underestimate the authority of feeling over music. But this [aroused] feeling, which in fact to a greater or lesser degree unites itself with pure contemplation, can only be regarded as artistic when it remains aware of its aesthetic origin, i.e., the pleasure in just this one particular beauty. If this awareness is lacking, if there is no free contemplation of the specifically musical beauty, and if feeling thinks of itself as only involved in the natural power of tones, then, the more vigorously the impression makes its appearance, all the less can art ascribe such impression to itself.' See OMB, p. 58, OML, p. 131-2.

70 According to Hanslick, the aesthetical significance of a response to music does not depend on whether emotions are aroused, but rather on whether it involves active and aware observing, perceiving of the specificities of the work, the awareness of the beauty of the work and listening to the piece only for its own sake, or, on the contrary, passive enjoyment in the general character of the piece, without noticing its specificities, as well as listening to the piece for the sake of enjoying one's own emotions that do not take music as their object OMB, p. 63-6, OML, p. 141-5.

71 See Budd, op. cit, p. 31.

$72 \mathrm{Ibid}$, p. 32. By improper descriptions Budd means that their use involves an essential reference to the emotions, and by deletable that they can be replaced by sets of terms drawn from different realms, which would serve exactly the same purpose. These other sets are in turn deletable in favour of purely musical, that is, literal, characterizations.

73 Ibid, p. 31-5.

$74 \quad$ Ibid, p. 31. 
„we can also take our descriptions from other realms of appearance," as meaning that there is no special reason why, say, „sad” should be used to stand for some property, since the term is no more appropriate than many other words. ${ }^{75} \mathrm{I}$ interpret the same sentence to mean that we generally describe music by using terms concerning various realms of phenomena, and so that emotional terms are simply not the only set of terms we use to describe music. According to my interpretation, Hanslick does not take the descriptions which contain emotional terms to be deletable, but rather believes that some descriptions of music can contain terms concerning emotions, while others can contain terms concerning weather conditions or some other realms of phenomena, and that descriptions themselves do not imply some special relation between music and those phenomena in any of the realms. Therefore, since emotional terms are not the only set of terms we use to describe music, there is no reason to believe that the mere fact that we describe music using emotional terms could imply that music is in some aesthetically relevant relation only with emotions. My interpretation, as opposed to Budd's, not only renders this passage coherent with other Hanslick's statements, but also has more support in the text of the treatise. ${ }^{76}$

Another significant intepreter of Hanslick's statements is Peter Kivy, who considers Hanslick's intentions so unclear that he dedicated a whole paper to figuring out what Hanslick even tried to deny in his treatise. Kivy's interpretation is supposed, among other things, to patch up many apparent contradictions that arise between the arguments of the negative thesis and the rest of the treatise. Kivy states that there are three clearly discernible arguments that weave in and out of Hanslick's negative thesis (although, because of the vagaries of Hanslick's style, he allows the possibility of there being more arguments), and all three are directed against the possibility of representation of emotions by music. ${ }^{77}$

The argument Kivy marks as the first one was, in my interpretation, concerned with the justification for ascribing any particular emotional content to an artwork. Kivy, however, names it „the argument from disagreement” and presents it as follows: if music could represent emotions, there would be general agreement on what, in any given instance, a piece or passage of music represents. However, since, according to Hanslick, there is complete, chaotic disagreement, music cannot sensibly be thought to represent emotions. ${ }^{78}$ Kivy refutes this argument by claiming there is no such disagreement. Besides oversimplifying this argument, Kivy fails to notice the already mentioned consequence of some possible disagreement: that if any two listeners disagree on which emotion is represented by a composition, the music itself does not provide a criterion

75 Ibid, p. 33.

76 See OMB, p. 32, OML, p. 90-1: "Feelings are thus, for the description of musical characteristics, only one source among others which offer similarities. We may use such epithets to describe music (indeed we cannot do without them), provided we never lose sight of the fact that we are using them only figuratively and take care not to say such things as 'This music portrays arrogance,' etc."

77 See Peter Kivy, 'What was Hanslick Denying', The Journal of Musicology, Vol. 8, No. 1 (1990), pp. 3-18, p. 6. (in further text WWHD)

$78 \quad$ Ibid, p. 7. 
for determining who of them is correct. Because there is nothing in the tones themselves that would unambiguously point out to some definite emotion (in Hanslick's words, „there is no necessary connection”), there is nothing we can use to justify the decision. Hanslick does not claim there is a "complete, chaotic disagreement" on what is the content of musical compositions, but rather that the issue of music's emotional content would be much simpler and more evident if music could represent definite emotions. I believe that this version of the argument has more strength than Kivy's version, and also puts forward a much more interesting observation than it would if it was merely noting a statistical fact about the agreement or disagreement of the listeners. On top of all this, my version is supported by Hanslick's explicit mentioning of justifying and refuting attribution of emotional content to musical compositions. ${ }^{79}$

The second argument concerns the re-use of music by the composers to set the texts of disparate emotive content or tone. Kivy presents it as an argument trying to demonstrate that, since in those cases the disparity between the old music and the new text is not perceived, it follows that music must be emotively "neutral". ${ }^{80}$ Kivy takes Hanslick's statement that we can imagine a dramatically effective melody which is supposed to express anger, but might also just as effectively suit words expressing the exact opposite, say, passionate love, to mean that every vigorous melody well suited to passionate anger is always well suited (on the same account) to passionate love. ${ }^{81} \mathrm{I}$ believe that this interpretation oversimplifies the argument, and presents the conclusion incorrectly. It turns out that, in Kivy's version, Hanslick claims something that is clearly false (that music is emotively neutral) and contradicts his own descriptions of music, and, on top of that, uses the examples that quite obviously do not prove his point. In addition, there are passages in the treatise which evidently show that for Hanslick music can be more or less expressive of some emotions, but even when it is expressive to a great extent, it is still insufficient for the achievement of one definite emotion. ${ }^{82}$ According to my interpretation, Hanslick characterizes music as emotively indefinite, rather than neutral. This is the conclusion that he (successfully, I believe) supports with examples of the same music suiting texts with a different emotional content. Moreover, my version of the argument is coherent with the rest of the treatise. This passage is related to Hanslick's statement that Gluck could have chosen tones more specific for the expression of passionate grief for Orpheus' aria. ${ }^{83}$ Kivy dedicates another paper to the clarification of

79 See OMB, p. 12-14, OML, p. 63-65.

80 Kivy, op. cit, p. 8.

81 Ibid, p. 8-9. Kivy easily refutes this version of the argument by giving a counterexample a musical passage that would not suit the words expressing love as it suits the words that express anger.

82 See OMB, p. 18, OML, p. 69: “(...) music certainly possesses far more specific tones for the expression of passionate grief." Also: "But even far more specific and expressive (bestimmtere und ausdrucksvollere) passages of vocal music will, when separated from their texts, at best only allow us to guess which feelings they express. They are like silhouettes whose originals we cannot recognize without someone giving us a hint as to their identity." 
this statement, since it does not fit his interpretation of Hanslick's view on the expressiveness of music. ${ }^{84}$ In this paper, Kivy tries in many ways, but with no success, to fit this statement with the rest of his interpretation of Hanslick's view, and ends by concluding that Hanslick was simply being incoherent. ${ }^{85} \mathrm{I}$ believe that this reaffirms that Hanslick's view is not only more coherent, but also easier to understand in my interpretation. ${ }^{86}$

The third argument is the already presented argument concerning the conceptual content of emotions. In Kivy's version, this argument demonstrates the impossibility of musical representation of emotions based on what emotions are and how they are ordinarily aroused. After noting that a good deal of Hanslick's view on emotions is "murky," Kivy supposes that Hanslick probably wanted to say that, since music cannot represent in sufficient detail the situations in which emotions are normally aroused, it cannot be thought to represent emotions. To this Kivy objects that the two claims clearly are not equivalent. ${ }^{87}$ Kivy's interpretation not only renders this argument unclear and quite bad, it is also not supported by the text of the treatise. When speaking of the conceptual content, Hanslick does not mention the situations in which emotions are aroused, but rather the conceptions and thoughts which appear in association with the emotion, during the occurrence of the emotion, although Hanslick adds that they can appear also unconsciously. Because of the latter, I am inclined to take the conceptual content as also the conceptions and thoughts we ordinarily associate with the concept of an emotion. ${ }^{88}$ Thus, according to my interpretation, the conceptual content is not the situation which arouses the emotion, nor is it necessarily in the consciousness of the person undergoing the emotion, but rather it is something we are inclined to associate with the emotion, or with the concept of that emotion. Jenefer Robinson, as well as Kivy, interprets this argument with the emphasis on the theory of emotions, especially on the

84 See Peter Kivy, 'Something I've Always Wanted to Know About Hanslick', Journal of Aesthetics and Art Criticism 46 (1988), p. 413-17.

85 Ibid, p. 416-7.

86 In order to show that this argument indeed succeeds in demonstrating the so-called emotive indefiniteness, I want to add that Hanslick emphasizes that he selected this example out of many, "first, because it concerns the composer - Gluck - to whom has been attributed the greatest exactitude in dramatic expression and, second, because over the years so many people have admired in this melody the feeling of intense grief which it expresses in conjunction with those words." It is clear from this that the melody which would much more suit the expression of one emotion was evidently very successful for the expression of another, completely different emotion - see OMB, p. 18, OML, p. 69.

87 Kivy, WWHD, p. 9-10.

88 Hanslick did not explicitly formulate the statement that conceptual content is not solely a part in the experience of emotion, but also the content we are usually inclined to associate with the concept of the emotion. However, I believe that this statement can still be ascribed to him, since it renders his argumentation more coherent, which I will substantiate further in the paper.

For the passage that goes against Kivy's interpretation, see OMB, p. 9-10, OML, p. 57-8: "Only on the basis of a number of ideas and judgements (perhaps unconsciously at moments of strong feeling) can our state of mind congeal (verdichten) into this or that specific feeling." 
arousal of emotions: Hanslick anticipates the judgement theory of emotions, according to which judgement is an essential component of the emotion, and the emotions are caused by a judgement. Her version of Hanslick's argument is that music cannot represent definite feelings because it cannot represent the specific representations or concepts that define particular emotions. ${ }^{89}$ Robinson believes this argument is refuted solely because psychology and neuroscience reject the theory of emotions she believe is the basis of this argument by showing that the judgement occurs in the later part of the emotion process. ${ }^{90}$ I do not want to engage in questioning how occurring of the components of emotions in a different order affects the definition of emotions, but rather just restate my belief that discussions between different psychological theories do not have a significant impact on the validity of Hanslick's argument. Hanslick does not specify what exactly he believes emotions are, what they consist of, how they arise or proceed. Robinson herself notices that Hanslick's view on the music's influence on out moods can be compatible with the results of psychological research she relies on, and which allegedly refute the cognitive theory of emotions. ${ }^{91}$ Therefore, I believe that, whichever theory of emotions we choose, we distinguish between the emotions primarily in the way Hanslick (in my interpretation) claims. This makes refuting any background theory of emotions by itself insufficient for the rejection of Hanslick's argument. ${ }^{92}$ It should also be noted that this is the only argument Robinson presents, and the only one other authors take to posses certain strength as well.

Steven Davies too mentions it as the only somewhat convincing argument. ${ }^{93}$ In his detailed review of the literature on music concerning musical meaning and the expression of emotions by music, Davies presents other Hanslick's arguments as well, but this is consisted almost solely in combining Budd's and Kivy's interpretations. ${ }^{94}$ Since Davies does not give any significant original contribution to the reconstruction of Hanslick's argumentation, I do not find it necessary to present parts of his review, but I think it should be noted that Davies'

89 See Jenefer Robinson, Deeper than Reason, Oxford NY, 2005, str. 295.

90 Ibid, p. 3, 7-8. These surveys have, according to Robinson, showed that emotions are processes in which a special kind of affective appraisal induces characteristic physiological and behavioral changes, and only afterwards is this succeeded by the so-called "cognitive monitoring" of the situation.

91 Ibid, p. 462, fn 7.

92 Therefore, instead of redefining the emotions (since this may leave the assumptions of the argument untouched), one should rather try to refute this argument by showing there is something besides the conceptual content that can be determinant for a particular emotion (that music can convey), that is, by finding some other criterion for distinguishing emotions.

93 See Davies, op. cit, p. 209.

94 Ibid, see p. 152-3. for the argument on eliminability of the descriptions of music involving emotion related terms (taken over from Budd); p. 203-208. for the argument on the relation between music and text (taken from Budd and Kivy); 209-221. for the main argument about the conceptual content (taken from Budd); p. 246-9. for the so-called argument from disagreement (taken from Kivy); p. 281-283. and 289-291. for the interpretation of Hanslick's view on the arousal of emotions (taken from Kivy). 
book at least indicates the acceptance and the influence of the interpretations presented in this paper.

\section{Conclusion}

I hope, first of all, that in this paper I succeeded in presenting a clear reconstruction of Hanslick's view on music - a reconstruction that renders his statements comprehensible and coherent, and thus in presenting Hanslick as a far better philosopher than contemporary interpreters give him credit for. Moreover, this would justify his role in the history of aesthetics in terms of philosophical significance, and not solely due to the fact that no one has hitherto had a serious approach to the aesthetics of music.

Due to the space limit, I was not able to expose all the details of contemporary author's interpretations of Hanslick's view. Nevertheless, I consider the material presented in this paper substantiated and sufficient for showing that it is not the fact that these interpretations contain some minor misunderstandings, but it is rather the whole argumentation that is misinterpreted. On the one hand, this renders their rejection of Hanslick's argumentation understandable, but, on the other hand, it indicates the possible need for a reconsideration of the same arguments, that is, the version of the arguments in which they are substantiated and coherent with each other.

I hope as well that I succeeded in the main intention of this paper, namely, to demonstrate that contemporary aesthetics of music (more precisely, the part of it that deals with the relation between music and the emotions) rests on the misinterpretation of Hanslick's statements, which should have an impact on the alleged refutations of those statements, and also on the soundness of the theories that count on the incorrectness of Hanslick's argumentation.

\section{References:}

Malcolm Budd, Music and the Emotions: The Philosophical Theories, London, 1985. Eduard Hanslick, Vom Musikalisch-Schönen, 13-15. Auflage, Leipzig, 1922.

Eduard Hanslick, On the Musically Beautiful, trans. Geoffrey Payzant, Indianapolis, 1986.

Eduard Hanslik, O muzički lijepom, pr. Ivan Foht, BIGZ, 1977.

Stephen Davies, Musical Meaning and Expression, Ithaca NY, 1994.

Peter Kivy, 'Something I've Always Wanted to Know About Hanslick', Journal of Aesthetics and Art Criticism 46 (1988), 413-17.

Peter Kivy, 'What was Hanslick Denying', The Journal of Musicology, Vol. 8, No. 1 (1990), pp. 3-18.

Jenefer Robinson, Deeper than Reason, Oxford NY, 2005.

Ludwig Wittgentstein, Philosophical investigations, Basil Blackwell Ltd 1958. 